\title{
Strategic Analysis of Products Related to the Integration of Human Judgement into Demand Forecasting
}

\author{
Séverine Meunier Martins, Naoufel Cheikhrouhou and Rémy Glardon \\ Swiss Federal Institute of Technology at Lausanne, Laboratory for Production Management \\ and Processes, Ecublens, CH-1015 Lausanne, Switzerland. \\ Email: severine.meunier@epfl.ch
}

\begin{abstract}
For companies proposing a large offer of products and services, it is important to identify the products for which the forecast quality is critical. The objective of this paper is to propose a strategic analysis of the products in order to determine priorities in the demand forecasting process: (1) a high priority class including the products for which forecast accuracy has a strong impact on the logistic performance of the company and where judgement should be integrated in the forecasting process; (2) a low priority class with the remaining products for which forecast accuracy is less important and where forecasts could be established in an automated way. The classification process takes into account different criteria chosen on the basis of cost efficiency reasoning.
\end{abstract}

Key words: Judgement in forecasting, Strategic analysis, Fuzzy classification

\section{INTRODUCTION}

Most of the mathematical forecasting models consist of more or less complex extrapolation techniques and are based on the hypothesis that established patterns in the previous data will not change during the forecasting phase and are expected to continue in the future. The context in which companies evolve nowadays is characterised by a high uncertainty level and quick changes in the environment for which this hypothesis is generally insufficiently verified. Under these conditions, integrating judgmental forecasts established by a forecaster on the basis of his/her interpretation of 
contextual information, his/her knowledge of the market and his/her experience, with mathematical forecasts appears promising; it would in particular allow the anticipation of changes in the demand characteristics and thus to increase the reliability and accuracy of the resulting forecasts (MEUNIER MARTINS 2003).

The integration of human judgement into mathematical forecasts can be very costly if a forecaster has to review every product. Furthermore, this systematic process could be inefficient as the forecaster would become bored with this mass of work. It is therefore crucial to identify the most important products for which the forecast quality is critical and where judgement should be integrated. This paper proposes a strategic analysis of the products in order to define priorities in the forecasting process. Two classes of finished products are determined:

- A high priority class including the products for which forecast accuracy has a strong impact on the logistic performance of the company and where judgement should be integrated into the forecasting process;

- A low priority class with the remaining products for which forecast accuracy is less important and where forecasts could be established in an automated way, without any human supervision.

This paper is organised in five sections. In section 2 , the justification and motivation for a strategic analysis of the products related to the integration of human judgement into demand forecasting are detailed. The classification criteria are also presented in this section with the reason of their choice. Section 3 introduces the classification problem with regards to some known approaches. Then the new classification method based on fuzzy logic and proposed in this paper is presented and justified. The presentation of a case study with data supplied by two companies is given and discussed in section 4. Finally, conclusions are presented in section 5.

\section{STRATEGIC ANALYSIS OF PRODUCTS}

The classification criteria are chosen on the basis of cost efficiency reasoning that could be illustrated by the question: how far do the resources invested in judgmental forecasting contribute to improved logistic performances and better service level? Three types of criteria have therefore been taken into account in the classification process. They are related to the:

- Strategic importance of the products for the company;

- Difficulty to establish forecasts (judgmental or mathematical);

- Influence of the forecasts accuracy on the logistic performance of the company. 
The criteria related to the strategic importance of the products for the company are the contribution of a product to the total turnover and its position in the life cycle. The contribution of the products to the total turnover identifies the items making the greatest part of the financial volume. The position of the product in the life cycle is a subjective criterion complementary to the previous one. It makes it possible to identify the items with a strong potential or dying, whereas this information does not appear clearly when evaluating their contribution to the total turnover.

The criteria relating to the difficulty in establishing reliable judgmental or mathematical forecasts are respectively the availability of useful contextual information and the randomness of the time series pattern related to the historical demand for a product. Many studies show that the availability of contextual information is crucial for the forecaster to establish reliable forecasts (SANDERS, RITZMAN 1992; EDMUNDSON et al. 1988). Although the randomness of the time series pattern does not completely evaluate the difficulty to establish accurate mathematical forecasts, this information presents the advantage of simplicity and indicates with a reasonable probability if the hypothesis for the use of extrapolation techniques for forecasting is met. The criterion "availability of contextual information" is subjective whereas the "randomness of the time series pattern" can be evaluated with statistical tests.

The criteria related to the influence of the forecast accuracy on the logistic performance of the company are the lead time of the constituting components of the products and their commonality, i.e. their level of standardisation. Many other criteria could be chosen in considering the role of forecast accuracy on the logistic performances. The choice of the former criteria is based on the fact that the upstream part of the supply chain (supply) depends most strongly on forecasts and requires longer term forecasts for long delivery lead time components. Furthermore, the commonality of the constituting components is important, as products made of specific components require more accurate forecasts than the others (ZIPPER, MEUNIER MARTINS 2002).

\section{CLASSIFICATION METHOD}

\subsection{State of the Art}

Single criterion $A B C$ classification based on the financial or material flow is the most popular and used technique for the classification of items in stocks. The great popularity of this procedure is explained by its simplicity; 
nevertheless it suffers a major drawback: only one criterion is taken into account.

FLORES and WHYBARK (1986) propose a derived approach from the $A B C$ classification. They use several classification criteria as the delivery lead time of the components, their possibility to be substituted, etc. FLORES et al. (1992) propose the use of a matrix in order to integrate two criteria in the classification process, for example the annual turnover and the lead time. Nine classes of items are determined, requiring nine different policies. This procedure becomes difficult to manage for more than two criteria.

Analytical Hierarchy Process (AHP) developed by SAATY (1980) has been successfully used by FLORES et al. (1992) and GAJPAL et al. (1994) for multi-criteria classification. They use AHP to reduce the different criteria in a unique and quantifiable measure, allowing them to classify the items according to the structure of a simple $\mathrm{ABC}$ classification. AHP requires a lot of subjectivity in the pair wise comparisons of the different criteria. It may be difficult for the expert to judgementally compare two criteria and assign them an objective weight according to their relative importance.

GUVENIR and EREL (1998) propose the use of genetic algorithms for the determination of the weights assigned to the AHP classification criteria. They are determined according to the frontier points between the A-B and B$C$ classes of a pre-classified set of items. The main inconvenient of this method is that it requires a pre-classification of a sample set of items.

\subsection{Proposed Classification Method}

In real cases of classification, there is often no absolute demarcation between the different classes that generally overlap. Fuzzy classification is appropriate for such situations where elements characterised by continuous data can not be clearly assigned to discrete classes and makes it possible to use linguistic criteria vaguely defined (ZADEH 1965). It consists in evaluating the compatibility of the different products to the two classes on a $[0 ; 1]$ interval.

This operation is done in two steps. Firstly, an elementary compatibility measure is processed for each product according to each classification criterion. The elementary compatibility measures are calculated according to membership functions on a $[0 ; 1]$ interval. The membership functions $\mu_{L P}^{c}\left(x_{c}\right)$ and $\mu_{H P}^{c}\left(x_{c}\right)$ give respectively the elementary compatibility measures of the item $x$ o the sub-classes of low and high priority according to the criterion $c$ and with a value $x_{c}$ for this criterion.

Secondly, the global membership levels to the two classes (high and low priority) are calculated for each product as a linear combination of their respective elementary compatibility measures. Generally, an average of the 
compatibility measures is used. This approach is sufficient if the classification criteria are independent and of equal importance.

Once the membership levels have been evaluated, a threshold defining the limit between the items of the low and high priority classes must be defined. This threshold corresponds to the value of the membership level to the high priority class above which the items will be considered as high priority ones. It is defined in order to minimise the number of products in the high priority class and maximise the number of components concerned with the forecasts established for these products.

\subsection{Definition of the Membership Functions}

\subsubsection{Criterion 1: Contribution of the Product to the Total Turnover}

This criterion has been chosen so that greater attention in the forecasting process goes to the products generating the more important part of the turnover. Generally, $20 \%$ of the products make $80 \%$ of the turnover (Pareto's law). The membership functions corresponding to the criterion "contribution to the total turnover" are defined according to the values defining the transition interval between the critical and non-critical items. After a classical $\mathrm{ABC}$ analysis, the lower and upper values defining this interval, respectively $S_{1}-\Delta_{1}^{\text {inf }}$ and $S_{1}+\Delta_{1}^{\text {sup }}$ are fixed. The corresponding membership functions to the low and high priority sub-classes, respectively $\mu_{L P}^{1}\left(x_{1}\right)$ and $\mu_{H P}^{1}\left(x_{1}\right)$, are illustrated in Figure 1 and defined in detail below.

$$
\begin{aligned}
& \mu_{L P}^{1}\left(x_{1}\right)= \begin{cases}1 & x_{1} \leq S_{1}-\Delta_{1}^{\text {inf }} \\
1+\left(S_{1}-\Delta_{1}^{\text {inf }}-x_{1}\right) /\left(\Delta_{1}^{\text {inf }}+\Delta_{1}^{\text {sup }}\right) & S_{1}-\Delta_{1}^{\text {inf }}<x_{1}<S_{1}+\Delta_{1}^{\text {sup }} \\
0 & S_{1}+\Delta_{1}^{\text {sup }} \leq x_{1}\end{cases} \\
& \mu_{H P}^{1}\left(x_{1}\right)= \begin{cases}0 & x_{1} \leq S_{1}-\Delta_{1}^{\text {inf }} \\
1+\left(x_{1}-S_{1}-\Delta_{1}^{\text {sup }}\right) /\left(\Delta_{1}^{\text {inf }}+\Delta_{1}^{\text {sup }}\right) & S_{1}-\Delta_{1}^{\text {inf }}<x_{1}<S_{1}+\Delta_{1}^{\text {sup }} \\
1 & S_{1}+\Delta_{1}^{\text {sup }} \leq x_{1}\end{cases} \\
& S_{1} \quad \begin{array}{l}
\text { Contribution of a product corresponding to the maximum difference between } \\
\text { the slopes of two successive points in the cumulative sum of the individual } \\
\text { contribution to the turnover }
\end{array} \\
& S_{1}-\Delta_{1}^{\text {inf }} \quad \begin{array}{l}
\text { Contribution of a product corresponding to the inferior limit of the transition } \\
\text { zone between the products making the smallest and the greatest part of the } \\
\text { turnover }
\end{array}
\end{aligned}
$$


$S_{1}+\Delta_{1}^{\text {sup }} \quad$ Contribution of a product corresponding to the superior limit of the transition zone between the products making the smallest and the greatest part of the turnover

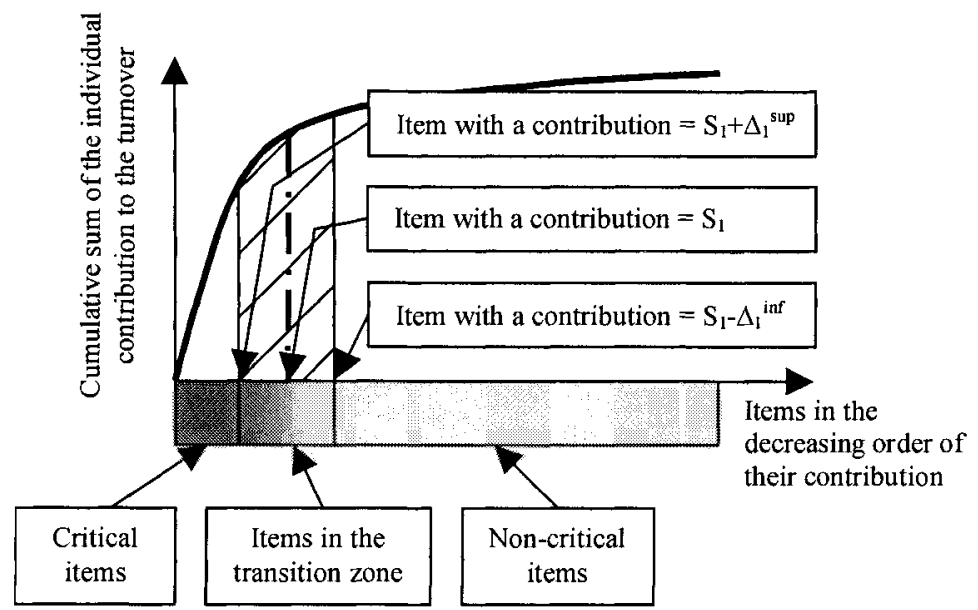

..... Membership function for the critical item group

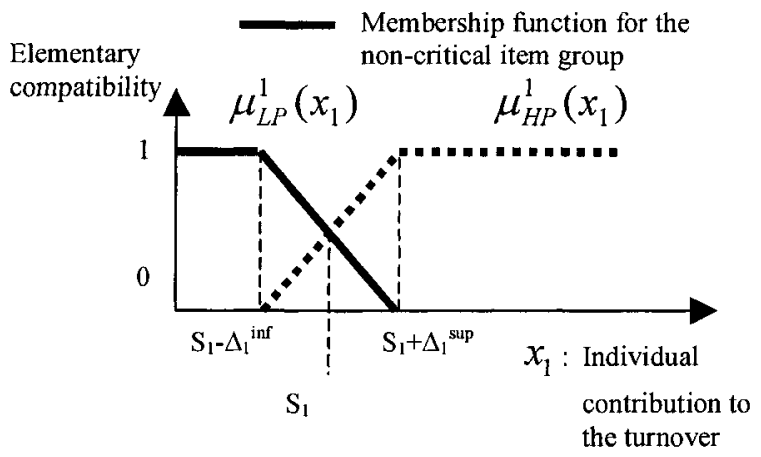

Figure l. Membership functions for the criterion "contribution to the turnover" (Source: MEUNIER MARTINS, CHEIKHROUHOU, GLARDON 2003, p. 199)

\subsubsection{Criterion 2: Position in the Life Cycle}

The products in a growing or decreasing phase should receive special attention in the forecasting process in order to limit forecast errors generating high costs (stock outs, over inventories difficult to use/sell, etc.) 
The value of this criterion is judgmentally evaluated on a 1 to 5 scale. The value 5 means that the considered product is in a strongly growing phase, whereas the value 1 means that it is dying. The value 3 indicates a stable position of the product. The membership functions corresponding to this criterion are depicted in Figure 2.

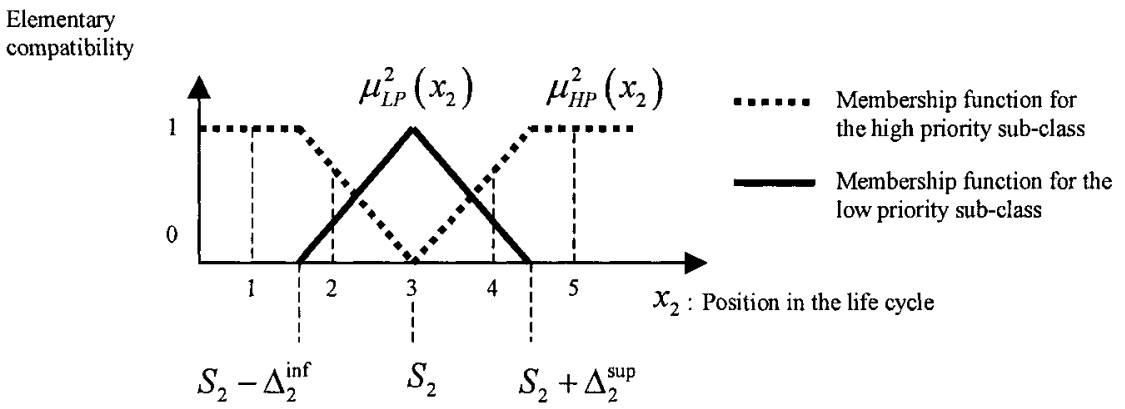

Figure 2. Membership functions for the criterion "position in the life cycle"

$S_{2} \quad$ Position in the life cycle corresponding to a stable phase

$S_{2}-\Delta_{2}^{\text {inf }} \quad$ Inferior limit of the transition zone between the growing and the stable phase

$S_{2}+\Delta_{2}^{\text {sup }}$ Superior limit of the transition zone between the stable and the decreasing phase

\subsubsection{Criterion 3: Availability of Useful Contextual Information}

Contextual information is very difficult to integrate into the forecasts unless interpreted by an expert and judgmentally combined with the forecasts. The value of the criterion "availability of contextual information" is judgmentally evaluated on a 1 to 5 scale. The value 5 means that a lot of significant contextual information is available for demand forecasting; on the opposite the value 1 means that no useful contextual information is available. Therefore, products for which this information exists should be supervised by an expert in the forecasting process. The membership functions corresponding to this criterion are depicted in Figure 3. 


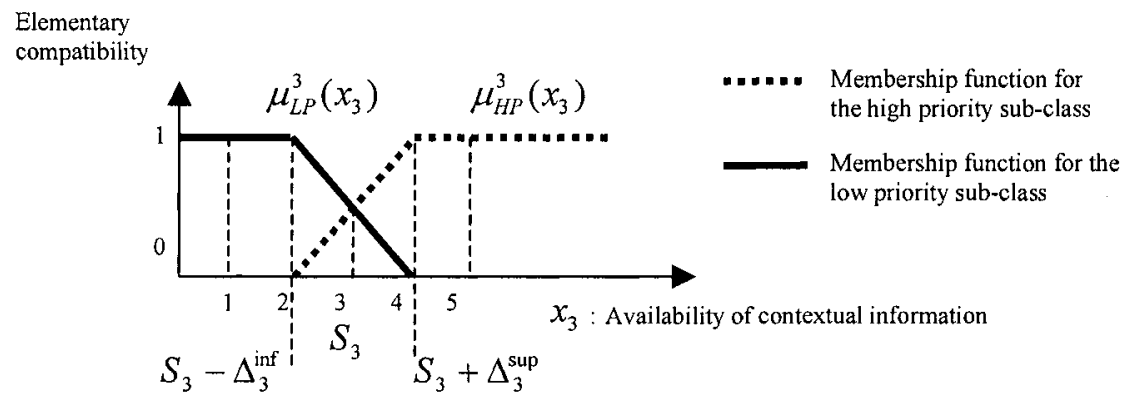

Figure 3. Membership functions for the criterion "availability of contextual information"

$S_{3} \quad$ Medium value concerning the availability of contextual information

$S_{3}-\Delta_{3}^{\text {inf }}$ Inferior limit of the transition zone between the non-availability and availability of information

$S_{3}+\Delta_{3}^{\text {sup }}$ Superior limit of the transition zone between the non-availability and availability of information

\subsubsection{Criterion 4: Randomness of the Time Series Pattern Related to the Historical Demand}

Extrapolation forecasting models should be applied only to time series having a non random pattern. The turning point test (KENDALL 1990) is used to check whether the time series pattern is random or not. A turning point in a time series is a point where the series changes direction, each turning point represents either a local peak or a local trough. This method is based on the premises that a trended or positively auto-correlated series should have fewer turning points than a random one and a negatively autocorrelated series should have more. If the series is actually a random series, the sampling distribution of the number of turning points $U$ is approximately normal. We define:

$$
Z=\left|\frac{U-\mu_{U}}{\sigma_{U}}\right|, \mu_{U}=\frac{2(n-2)}{3}, \sigma_{U}=\sqrt{\frac{16 n-29}{90}}
$$

where $\mu_{U}$ and $\sigma_{U}$ are respectively the expected value and variance of $U$ and $n$ is the number of observations of the time series. 
The probability that the time series pattern is random is higher than $90 \%$ if $Z<Z_{\alpha / 2}, Z_{\alpha / 2}=1.282$. The membership functions corresponding to the criterion "randomness of the time series" are depicted in Figure 4.

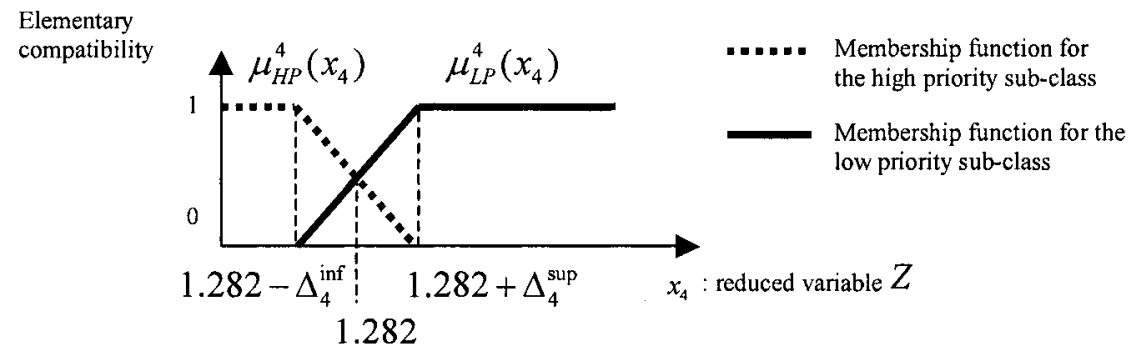

Figure 4. Membership functions for the criterion "randomness of the time series pattern"

$S_{4} \quad$ Threshold value above which the probability that the time series pattern is random is higher than $90 \%$

$S_{4}-\Delta_{4}^{\text {inf }} \quad$ Inferior limit below which the time series pattern is considered as random

$S_{4}+\Delta_{4}^{\text {sup }}$ Superior limit above which the time series pattern is considered as nonrandom

\subsubsection{Criterion 5: Delivery Lead Time of the Constituting Components}

The membership functions corresponding to the criterion "delivery lead time of the constituting components" are respectively $\mu_{H P}^{5}\left(x_{5}\right)$ and $\mu_{L P}^{5}\left(x_{5}\right)$ for the high and low priority sub-classes and are shown in Figure 5.

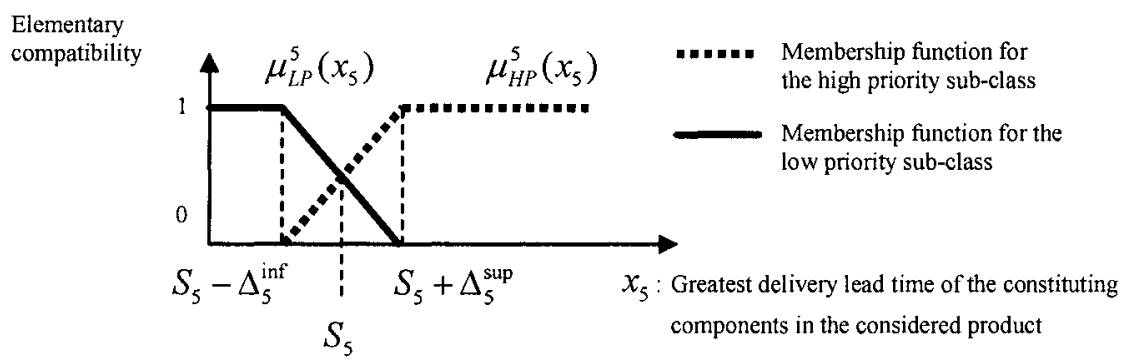

Figure 5. Membership functions for the criterion "delivery lead time of the constituting components"

$S_{5} \quad$ Threshold corresponding to the component delivery lead time considered as critical by the company (in regard to the product delivery time for example) 
$S_{5}-\Delta_{5}^{\text {inf }} \quad$ Inferior limit of the critical delivery lead time

$S_{5}+\Delta_{5}^{\text {sup }} \quad$ Superior limit of the critical delivery lead time

\subsubsection{Criterion 6: Commonality of the Components}

The commonality of a component is defined as the ratio between the number of products including the considered component to the total number of products; the lower the commonality, the more specific the component. The criticality of a product made up of $m$ constituting components with commonality $c_{i}(i=1 \ldots m)$ is defined as

$$
C=1 / m \sum_{i=1}^{m}\left(1 / c_{i}\right) \text {. }
$$

The results of a simulation study (ZIPPER, MEUNIER MARTINS 2002) show that the products requiring a particular attention in the forecasting process are the ones scoring a high criticality. In the classification process the number of products belonging to the high priority sub-class related to the criterion "commonality of the components" should be minimal and the population of related components should be maximal. The membership functions corresponding to the criterion "commonality of the components" are respectively $\mu_{H P}^{6}\left(x_{6}\right)$ and $\mu_{L P}^{6}\left(x_{6}\right)$ for the critical and non-critical item groups and are shown in Figure 6.

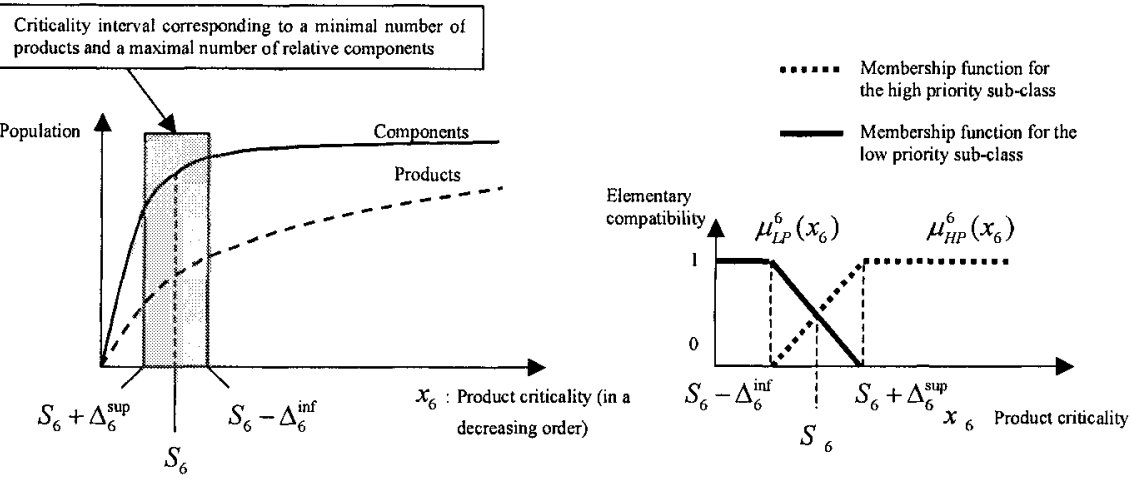

Figure 6. Relation between the criticality of the products and the populations of products and components

$S_{6} \quad$ Product criticality threshold

$S_{6}-\Delta_{6}^{\mathrm{inf}} \quad$ Inferior limit of the product criticality threshold

$S_{6}+\Delta_{6}^{\text {sup }} \quad$ Superior limit of the product criticality threshold 


\subsubsection{Final Classification}

As suggested in section 3.2., a simple average of the elementary compatibility measures is used to process the final membership levels of a product $x$ to the low and high priority classes, respectively $\mu_{L P}(x)$ and $\mu_{H P}(x)$ :

$$
\begin{aligned}
& \mu_{L P}(x)=\frac{1}{6}\left(\mu_{L P}^{1}\left(x_{1}\right)+\mu_{L P}^{2}\left(x_{2}\right)+\mu_{L P}^{3}\left(x_{3}\right)+\mu_{L P}^{4}\left(x_{4}\right)+\mu_{L P}^{5}\left(x_{5}\right)+\mu_{L P}^{6}\left(x_{6}\right)\right) \\
& \mu_{H P}(x)=\frac{1}{6}\left(\mu_{H P}^{1}\left(x_{1}\right)+\mu_{H P}^{2}\left(x_{2}\right)+\mu_{H P}^{3}\left(x_{3}\right)+\mu_{H P}^{4}\left(x_{4}\right)+\mu_{H P}^{5}\left(x_{5}\right)+\mu_{H P}^{6}\left(x_{6}\right)\right)
\end{aligned}
$$

\section{CASE STUDIES}

Real data from two Swiss manufacturing companies are used to provide real numerical examples of product classification. Company A designs and produces electric micro-motors. Company $\mathrm{B}$ designs and produces electronic sub-assemblies, sensors, etc. For company A, 1465 products are considered made up of more than 2600 components; 21 products made up with 1443 components are used for company B.

The membership levels to the low and high priority classes obtained for some of the products of the company B are presented in Table 1 .

Table 1. Example of the results for the membership levels to the low and high priority classes obtained for some of the products of company B

\begin{tabular}{|c|c|c|}
\hline Product & $\begin{array}{c}\text { Membership level to the } \\
\text { low priority class } \mu_{L P}(x)\end{array}$ & $\begin{array}{c}\text { Membership level to the high } \\
\text { priority class } \mu_{H P}(x)\end{array}$ \\
\hline 463000 & 0.053 & 0.947 \\
\hline 713317 & 0.224 & 0.776 \\
\hline 663288 & 0.410 & 0.589 \\
\hline 667173 & 0.734 & 0.266 \\
\hline
\end{tabular}

Table 2 shows the populations of products and related components with a membership level to the high priority class higher than a specific value. This table is very useful to define the threshold fixing a limit value in the high priority class above which the products will be considered as high priority in the forecasting process. This threshold should be chosen in order to minimise the number of high priority products and maximise the number of components related to these critical products. 
Table 2. Relation between the membership level to the high priority class (HP) and the corresponding populations of products and components

\begin{tabular}{|c|c|c|c|c|}
\cline { 2 - 5 } \multicolumn{1}{c|}{} & \multicolumn{2}{c|}{ Company A } & \multicolumn{2}{c|}{ Company B } \\
\hline $\begin{array}{c}\text { Membership } \\
\text { level HP }\end{array}$ & $\begin{array}{c}\text { Population } \\
\text { of products }\end{array}$ & $\begin{array}{c}\text { Population of } \\
\text { components }\end{array}$ & $\begin{array}{c}\text { Population } \\
\text { of products }\end{array}$ & $\begin{array}{c}\text { Population of } \\
\text { components }\end{array}$ \\
\hline 0.5 & $20.4 \%$ & $71.5 \%$ & $76.2 \%$ & $83.5 \%$ \\
\hline 0.55 & $18.9 \%$ & $70.5 \%$ & $71.4 \%$ & $83.2 \%$ \\
\hline 0.6 & $17.4 \%$ & $68.9 \%$ & $33.3 \%$ & $79.8 \%$ \\
\hline 0.65 & $16.7 \%$ & $66.9 \%$ & $33.3 \%$ & $79.8 \%$ \\
\hline 0.7 & $16.1 \%$ & $66.5 \%$ & $28.6 \%$ & $27.1 \%$ \\
\hline 0.75 & $2.9 \%$ & $26.9 \%$ & $4.8 \%$ & $5.2 \%$ \\
\hline
\end{tabular}

From these results, a good compromise for company A and company B seems to be obtained with a threshold value for the membership level to the high priority class equal to 0.6 (in grey in Table 2). Products with a membership level to the high priority class higher than 0.6 are considered as critical in the forecasting process. In this case the distribution of the population of products for company A and company B is shown in Figure 7.

Company A



Company B

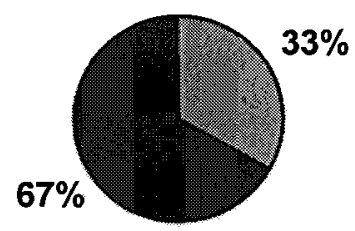

口 HP

- LP

Figure 7. Distribution of the products according to the high and low priority classes

The populations of components related to the products belonging to the low and high priority classes may be compared with the following financial criteria:

- Sum of the unit price of the components used to produce one unit of each product (FV1);

- Sum of the unit price of the components used to produce the products within one-year sales history (FV2). 
The results of this comparison are presented in Table 3.

Table 3. Financial volumes of the components related to the low and high priority product classes (LP and HP)

\begin{tabular}{|l|c|c|c|c|}
\cline { 2 - 5 } \multicolumn{1}{c|}{} & \multicolumn{2}{c|}{ Company A } & \multicolumn{2}{c|}{ Company B } \\
\cline { 2 - 5 } \multicolumn{1}{c|}{} & LP & HP & LP & HP \\
\hline $\begin{array}{l}\text { FV1: Total component cost related } \\
\text { to the production of one unit of each } \\
\text { product }\end{array}$ & $25.2 \%$ & $74.8 \%$ & $85.9 \%$ & $14.1 \%$ \\
\hline $\begin{array}{l}\text { FV2: Total component cost related } \\
\text { to one-year products sales }\end{array}$ & $14.2 \%$ & $85.8 \%$ & $32.7 \%$ & $67.3 \%$ \\
\hline
\end{tabular}

The results obtained for the company A confirms that the high priority products hit the components making the greatest part of the total financial volumes described above. For the company $\mathrm{B}$, the most expensive components are essentially included in the low priority products. It explains the poor result concerning the total component cost related to the production of one unit of each product. Nevertheless, when one-year sales history is analysed it appears that the high priority products hit the components making $67.3 \%$ of the supply turnover.

\section{CONCLUSIONS}

In this paper, a strategic analysis of the products related to the integration of human judgement into demand forecasting has been presented. This strategic analysis is based on a new classification approach based on fuzzy logic. This approach makes it possible to take into account the vagueness of some classification criteria as well as linguistic criteria. Various classification criteria can be taken into account in this process. We chose them in order to emphasise the critical elements for which the quality of the forecasts has a deep impact on the logistic performances of the company. Nevertheless, if the objective of the company is to improve the demand forecast accuracy in order to increase the reliability of supply management at the lowest costs, more specific criteria may be defined. For example the optimal supply management policy for each component may be another criterion for the selection of the high priority products. Once the criteria are chosen, elementary compatibility measures are calculated for each criterion and each product according to the high and low priority classes. Finally the membership levels to the high and low priority classes are determined for each product on the basis of a linear combination of its elementary compatibility measures. The 
results obtained with the data from two companies show firstly that this method can be applied successfully and secondly that the number of high priority products is limited in a drastic way, without penalising too much the related components. Further research would be needed to find out the influence of the choice of the various membership functions as well as to strengthen the validation of the proposed approach through other real case applications.

\section{ACKNOWLEDGEMENTS}

The authors thank the Swiss Agency of Promotion and Innovation for the financial support of the project "Socio-technical system improvement for the reliability of supply forecasts".

\section{REFERENCES}

EDMUNDSON, Robert; LAWRENCE, Michael; O'CONNOR, Marcus:

The use of non-time series information in sales forecasting: a case study.

In: Journal of Forecasting,

Chichester, 7(1988)2, pp. 201-211.

FLORES, Benito; OLSON, David; DORAI, V. K.:

Management of multicriteria inventory classification.

In: Mathematical and Computer Modeling,

London, 16(1992)12, pp. 71-72.

FLORES, Benito; WHYBARK, D. Clay:

Multiple criteria $\mathrm{ABC}$ analysis.

In: International Journal of Operations and Production Management,

Bradford, 6(1986)3, pp. 38-46.

GAJPAL, Prem; GANESH, L. S.; RAJENDRAN, Chandrasekharan:

Criticality analysis of spare parts using the analytical hierarchy process.

In: International Journal of Production Economics,

Amsterdam et al., 35(1984)1-3, pp. 293-297.

GUVENIR, H. Altay; EREL, Erdal:

Multicriteria inventory classification using a genetic algorithm.

In: European Journal of Operational Research,

Amsterdam, 105(1998)1, pp. 29-37.

KENDALL, Maurice; ORTH, J. Keith:

Time series, $3^{\text {rd }}$ edition.

London: Arnold, 3rd ed., 1990.

MEUNIER MARTINS, Séverine:

Approche stratégique pour la prevision de données de gestion: méthode ciblée integrant des elements subjectifs et mathématiques.

Lausanne: EPFL, PhD diss., 2003. 
MEUNIER MARTINS, Séverine; CHEIKHROUHOU, Naoufel; GLARDON, Rémy:

Strategic Analysis of Products Related to the Integration of Human Judgement into Demand Forecasting.

In: Current Trends in Production Management.

Eds.: ZÜLCH, Gert; STOWASSER, Sascha; JAGDEV, Harinder S.

Aachen: Shaker Verlag, 2003, pp. 196-203.

(esim - European Series in Industrial Management, Volume 6)

SAATY, Thomas :

The analytical hierarchy process.

New York, NY: McGraw-Hill, 1980.

SANDERS, Nada; RITZMAN, Larry :

The need for contextual and technical knowledge in judgemental forecasting.

In: Journal of Behavioural Decision Making,

Chichester, 5(1992), pp. 39-52.

ZADEH, Lotfi A.:

Fuzzy Sets.

In: Information and Control,

New York, NY, 8(1965)3, pp. 338-353

ZIPPER, Hélène; MEUNIER MARTINS, Séverine :

Analyse de la criticité des produits.

Internal report.

Lausanne: EPFL-LGPP, 2002. 